\title{
La selección de obras para la investigación en LIJ digital: de la teoría a la recepción ${ }^{1}$
}

\author{
Lucas Ramada Prieto \\ Universitat Autònoma de Barcelona \\ Celia Turrión Penelas \\ Universitat Autònoma de Barcelona
}

(Texto recibido el 3 de junio de 2019; aceptado el 28 de junio de 2019; versión final el 1 de julio de 2019)

DOI: https://doi.org/10.5565/rev/jt13.839

Resum: La ficció digital forma part central del consum cultural d'infants i adolescents, però, malgrat això, la mediació a partir d'obres digitals encara és escassa en l'àmbit escolar. Aquest article reflexiona sobra la selecció d'obres de literatura digital per a la formació de lectors infantils i juvenils, en el marc de l'actual projecte de recerca del grup GRETEL (UAB): "Ensenyar a llegir literatura digital". El text descriu les decisions adoptades i els obstacles salvats en relació amb aquest procés de selecció a partir de tres eixos: l'extracció de dades sobre estratègies de lectura, l'activitat formativa a l'aula a partir d'aquestes dades i l'anàlisi posterior de l'evolució de les seves competències. El text presenta $i$ analitza les obres utilitzades i proposa estratègies per evitar els principals problemes de la recerca en aquest àmbit.

Paraules clau: literatura infantil i juvenil; literatura digital; educació literaria; mediació literària

\begin{abstract}
Digital fiction is a central part of children's and adolescents' cultural habits, and yet mediation based on digital works is still missing in the school. This article reflects on the practice of selecting works of digital literature for children and young people to train readers in the framework of the current research project of the GRETEL group (UAB): "Teaching to read digital literature". The text describes the decisions that have been adopted and the obstacles that have been saved in relation to the process of selecting children's digital fiction works from three axes: the extraction of data on reading strategies, the training with children from these data and the subsequent analysis of the evolution of their competences. The essay presents and analyzes the works that have been employed and proposes strategies to overcome the main problems of research in this field.
\end{abstract}

Keywords: children's literature; digital literature; literary education; literary facilitation

Resumen: La ficción digital forma parte central en el consumo cultural de niños y adolescentes, y sin embargo la mediación a partir de obras digitales es aún escasa en el ámbito escolar. Este artículo reflexiona sobra la práctica de selección de obras de literatura digital para la formación de lectores infantiles y juveniles en el marco del actual proyecto de investigación del grupo GRETEL (UAB): "Enseñar a leer literatura digital". El texto describe las decisiones adoptadas y los obstáculos salvados en relación al proceso de selección de obras de ficción digital infantil a partir de tres ejes: la extracción 
de datos sobre las estrategias de lectura, la formación con los niños a partir de esos datos y el posterior análisis de la evolución de sus competencias. El ensayo presenta y analiza las obras empleadas y propone estrategias que permitan sortear los principales problemas de la investigación en este ámbito.

Palabras clave: literatura infantil y juvenil; literatura digital; educación literaria; mediación literaria

\section{Introducción}

A pesar de las dificultades para encontrar una definición consensuada de literatura infantil y juvenil digital (Ramada Prieto, 2017, p. 56), en los últimos años parece irse perfilando una descripción amplia, o al menos flexible, de este objeto de estudio. Las investigaciones sobre el campo se centran en destacar la necesidad de que las obras de LIJD sean experimentadas en formato digital (en contraposición a las digitalizadas) y de que los recursos expresivos que el medio electrónico permite se empleen creativamente y con presencia clara de una cierta literariedad (Turrión, 2014; Manresa y Real, 2015; Ramada Prieto, 2017; Torres et al., 2019).

Así, algunas obras de ficción generadas para todo tipo de soportes electrónicos entrarían potencialmente en la categoría de literatura digital dirigida a niños y jóvenes. Debido a la dispersión de estas obras en diferentes plataformas, a su existencia de diversos formatos y a la necesidad de diferentes tipos de dispositivos para acceder a ellas, la selección por parte de mediadores y por lo tanto el acceso a ellas por parte de los lectores de un modo sistemático con fines de educación literaria son tareas tremendamente complejas. Este panorama se contrapone al circuito social en el cual el contacto de los lectores actuales con obras de ficción digital como forma de ocio es recurrente y está en constante crecimiento. Concretamente, según la Asociación Española de Videojuegos, el 78\% de la población de entre 0 y 16 años consume ficción digital (Ramada Prieto, 2018a).

Sin embargo, la escuela va por detrás de este uso, y la inclusión de la ficción digital dentro del corpus de la formación literaria de niños y jóvenes es aún una realidad por cumplir de manera extensiva. A pesar de la existencia de obras adecuadas para este propósito, así como de investigaciones en nuestro entorno inmediato que han indagado en las características de estas obras y sus posibilidades para la formación literaria (Turrión, 2014; Manresa y Real, 2015; Ramada Prieto, 2017) pocas son aún las aplicaciones de las teorías expuestas en la realidad de las aulas. Es deber de investigadores y mediadores conocer la oferta ficcional dirigida a niños y jóvenes existente en el medio electrónico, así como comprender su funcionamiento y las posibilidades que ofrece en el marco de la educación literaria. 
Como ya hemos mencionado, la selección de obras de calidad en el medio electrónico se encuentra con diferentes barreras, desde las meramente materiales como la necesidad de equipos para acceder a las obras, hasta la ausencia de recursos de evaluación en plataformas de venta y en instituciones tradicionales ligadas a la literatura, pasando por el desconocimiento y los prejuicios individuales de los mediadores.

\section{Marco contextual de la investigación}

En este contexto surge el proyecto del grupo de investigación GRETEL de la Universitat Autònoma de Barcelona "Enseñar a leer literatura digital" dentro del Programa Estatal de Investigación, Desarrollo e Innovación orientada a los Retos de la sociedad (EDU2016-77693R). Con el claro propósito de contribuir a la formación de lectores y mediadores en las posibilidades que ofrece el medio electrónico para el aprendizaje literario, el proyecto cuenta desde el comienzo con tres objetivos principales que lo vertebran y que estructuran de igual manera el presente artículo.

El primer objetivo del citado proyecto consiste en identificar las estrategias lectoras digitales adoptadas por los niños frente a los tres rasgos definitorios de la ficción digital según investigaciones previas: multimodalidad, interactividad y discontinuidad (Turrión, 2014, 2015; Ramada Prieto, 2017, 2018b), y sus disfunciones respecto de la construcción de sentido. El segundo objetivo se centra en determinar las necesidades formativas de los docentes en literatura digital, transformando sus posibles reticencias y vacíos de conocimiento a partir de un modelo de formación docente participativo y contextual. Finalmente, el tercero incide en la práctica y pretende diseñar y evaluar intervenciones didácticas específicas en el aula que mejoren la comprensión e interpretación de las obras literarias digitales.

El presente artículo describe las decisiones adoptadas y los obstáculos salvados en relación al proceso de selección de obras de ficción digital infantil para la investigación en didáctica literaria dentro de un contexto metodológico que incluye dispositivos de extracción de datos sobre estrategias de lectura, el diseño de secuencias formativas para los niños a partir de esos datos y el posterior análisis de la evolución de sus competencias.

\section{Seleccionar obras para extraer datos sobre la construcción de sentido litera- rio}

En primer lugar, debían elegirse las obras con las que, primero, se realizaría la lectura de los textos por parte del alumnado seleccionado, y después, se diseñaría e implementarían los 
cuestionarios y las entrevistas. Esta etapa de la investigación trataba de encontrar las dificultades específicas que las obras proponen a su lector implícito para posteriormente identificar estrategias y dificultades en los lectores reales. Para ello, se decidió que las líneas definitorias de la LIJD establecidas por Turrión (2014) para la narrativa digital infantil y ampliadas por Ramada Prieto (2017) para toda la comunicación literaria infantil y juvenil digital marcarían los tres grandes ejes que organizarían la selección.

Para empezar, se puso el foco en la multimodalidad expresiva (Kress y Van Leuween, 2001), o el uso de diferentes códigos artísticos que en el medio electrónico pueden combinarse dando como resultado innumerables variaciones (Unsworth, 2006). En segundo lugar, se consideró la ruptura de la linealidad estructural y discursiva propia del medio digital (Landow, 2006; Ensslin, 2007). Finalmente, se tuvo en cuenta la participación activa del lectousuario propia de la recepción literaria en formato electrónico (Aarseth, 1997; Ryan, 2006; Planells, 2015).

Existe una cuarta propiedad definitoria de la LIJD, la nueva materialidad virtual que modifica todo lo relativo al hecho lector — como la objetualidad, paratextualidad, circulación y la manipulación (Hayles, 2008; Ramada Prieto, 2017) y que no tiene que ver ni con el discurso literario en sí, ni con el código utilizado- que no ha sido tenida en cuenta de manera individual dentro de la estructura metodológica de la investigación sino que ha formado parte de toda ella como un elemento de atención constante debido a su transversalidad y por las profundas implicaciones que tiene para los contextos de lectura y disfrute literario.

Junto al criterio teórico-descriptivo sobre el que pivota la selección, una vez elegido el contexto escolar en el que se desarrollaría la investigación, se establecieron una serie de criterios a partir de los cuales realizar la selección de obras:

1. Las obras deberían adaptarse al rango de competencias lectoliterarias medias pensadas para un contexto de ciclo superior de primaria.

2. Las obras debían tener una longitud que las permitiese ser leídas dentro de un contexto de aula de no más de 40 minutos.

3. Las obras debían estar en una de las lenguas co-oficiales del contexto de investigación (castellano y/o catalán) o carentes de lenguaje escrito para garantizar que el proceso de recepción literaria no se condicionaría por la presencia de una lengua ajena.

4. Las obras debían tener unos mínimos de calidad estética (a todos los niveles), pues partimos de la idea de que la educación literaria tiene en su corpus la materia prima de la que nace su ejercicio. Así, se ha de intentar disminuir los efectos que una calidad 
deficitaria del corpus puede tener sobre el hecho lector.

Para la primera de las líneas definitorias, la multimodalidad expresiva, se escogió la obra digital para ordenador Inanimate Alice (Pullinger y Joseph, 2005-2019). Esta obra es un referente en las aproximaciones de corte pedagógico a la literatura digital en ámbito internacional. Consta de seis episodios, varios de los cuales han sido traducidos al castellano. La obra narra la vida cotidiana de una familia desplazada de su hogar en capítulos que corresponden a los diferentes lugares donde van estableciendo su residencia. Si bien la estética de la obra puede resultar un tanto obsoleta, ofrece una combinación de lenguajes bastante sofisticada que puede favorecer aprendizajes relevantes sobre las posibilidades de configuración multimodal en digital.

La narración corre al cargo de Alicia, la hija de la familia, que en el primer capítulo tiene ocho años y que, mediante el texto escrito, relata las aventuras de su día a día. En esta obra las imágenes que acompañan a ese texto —que actúa como hilo conductor- cobran una especial relevancia al ofrecer diferentes perspectivas narrativas según la ocasión: focalización cero, focalización en la mirada de la niña, en la mirada del padre... Por su parte, el audio de la obra presenta música y sonidos tanto intradiegéticos (aquellos pertenecientes al mundo interno de la narración) como extradiegéticos, que ambientan la historia y añaden carga dramática potenciando el efecto de suspense, que es central en la obra. La suma de los tres códigos expresivos añade capas de interpretación a un texto que aparentemente refleja la inocencia de una niña y que, en realidad, juega con la simplicidad y la elipsis. Las interpretaciones de la obra que tienen en cuenta la combinación de lenguajes inciden en cómo la aparente ingenuidad de la niña no es tal, en cómo la pequeña se contagia del nerviosismo de los padres en los momentos críticos de la narración o en cómo la PDA (una agenda personal electrónica) que siempre la acompaña y las acciones que con ella realiza (a menudo con el lector como cómplice activo) funcionan como una estrategia de evasión de la peligrosa realidad que le ha tocado vivir.

Una de las principales limitaciones que nos encontramos en el proceso de selección de obras para extraer datos de los alumnos fue la falta de obras en castellano y catalán que cumpliesen con total satisfacción las necesidades mencionadas, especialmente en el ámbito de la participación del lector o interactividad expresiva. Por este motivo, se flexibilizó el criterio lingüístico para incluir obras que sí ofreciesen garantías de calidad suficientes para nuestro propósito. Así pues, para la segunda línea de caracterización, la ruptura de la linealidad estructural y discursiva, se escogió trabajar con la obra A Duck Has an Adventure (Merlin Goodbrey, 2012). A pesar de ser una obra en inglés, el valor de la obra no reside estrictamente en lo lingüístico, sino en lo estructural; el volumen de texto escrito es considerablemente bajo y su interpretación 
se puede complementar con el fuerte valor semántico de las ilustraciones icónicas que organizan el discurso multimedia.

El relato se estructura por casillas que incluyen un texto muy breve acompañado de una imagen en forma de icono y que se van desplegando y bifurcando en diferentes posibilidades a medida que el lectousuario va tomando decisiones acerca de la vida que el protagonista («un pato» intencionadamente sin nombre para mostrar lo prototípico del personaje). Las múltiples opciones que el pato va encontrándose en su(s) vida(s) y que se configuran como una estructura multilineal ofrecen muy diversas opciones de disfrute interactivo, gracias, además, al tono humorístico que impera en la obra. Un aspecto especialmente reseñable es cómo la configuración paratextual de la obra invita a la lectura exhaustiva, gracias a la posibilidad de hacer zoom hacia delante y hacia atrás y visualizar el progreso de la lectura individual respecto a la totalidad de la obra. Esta estructura redunda en el propio tema de la obra ironizando sobre la vida y el tan complejo como azaroso proceso de toma de decisiones.

Finalmente, merece la pena comentar cómo la simplicidad formal de esta obra se enriquece, además, con una propuesta intertextual con la literatura clásica y de aventuras marinas que sirve como trampolín para generar conexiones y elaborar relaciones entre productos culturales como parte del desarrollo de la competencia literaria de los lectores.

En tercer lugar, para abordar la participación activa del lectousuario, se seleccionó la obra The Empty Kingdom (Merlin Goodbrey, 2015). En este cómic lúdico sin más palabras que el título y una advertencia inicial (en inglés) de que el juego no está ya disponible, el lectousuario es empujado a navegar por las diferentes viñetas sin un objetivo concreto. La propia intencionalidad de la propuesta interactiva está oculta, ya que se presenta un mundo vacío en el que el avatar, que es el rey (se sabe por la corona que porta), se encuentra completamente solo. La reminiscencia a los cuentos tradicionales funciona en sentido negativo: no hay nada que hacer, no queda nada vivo, todo lo que ha pasado o potencialmente puede pasar está en la cabeza del lectousuario. La pausa temporal que supone habitar un reino vacío, los sonidos de la naturaleza y el silencio que acompañan en la lectura, junto con la constante repetición de numerosas acciones de desplazamiento, sitúan al lector en un punto opuesto al estrés del jugador de videojuegos. De este modo, a partir de generar sensaciones como el aburrimiento, el desconcierto o la frustración, la obra propone nuevos modos de interactuar e impulsa la actividad intelectual del lectousuario, que buscará una interpretación a ese vacío.

Existe, no obstante, un punto en el que el lectousuario puede resarcirse parcialmente de su frustración, pues durante el paseo sin rumbo el lectousuario va recogiendo algunos objetos 
como suele ocurrir en los videojuegos. Aunque no está claro el uso que puede darles, poco a poco observa cómo al pasar por ciertos lugares estos le son de utilidad. El punto de inflexión en la propuesta interactiva se encuentra cuando, en una de las casillas, el rey vislumbra otra figura humana más allá de su isla. Es entonces cuando el lectousuario puede comenzar a trabajar en el propósito de comunicarse con él y finalmente de alcanzar la otra orilla para reunirse con el único ser viviente de aquel mundo devastado.

Una vez detectadas las principales características y desafíos de estas obras, debíamos pasar al segundo punto, esto es, contrastarlas con los lectores.

\section{Seleccionar obras para formar lectores de LIJD}

Esta primera parte de la investigación pretendía extraer datos sobre las posibles dificultades y estrategias interpretativas que los niños y niñas podrían mostrar a la hora de construir sentido con las obras seleccionadas. Una vez desplegados los dispositivos de extracción de datos y analizados los resultados, se llegó a la conclusión de que, en líneas generales, las principales dificultades detectadas, en relación a cada una de las líneas definitorias de la LIJ digital eran las siguientes:

- En torno a la multimodalidad, se detectó que había un claro desequilibrio entre la forma en que el alumnado construía sentido a partir del lenguaje escrito y el resto de sustancias semióticas movilizadas en la obra utilizada, Inanimate Alice. Este desequilibrio se materializaba tanto en el nivel de complejidad que el alumnado era capaz de alcanzar a la hora de interpretar el lenguaje escrito (en detrimento de, por ejemplo, la imagen o la música), como en sus capacidades para explicitar estos procesos interpretativos cuando se les instaba a ello. Es decir, no solo tenían más dificultades para construir sentido a partir de sustancias no lingüísticas, sino que incluso cuando la interpretación a partir del resto de modos comunicativos sí se producía, no eran conscientes metarreflexivamente del proceso, o al menos no lo explicitaban en sus respuestas.

- A partir de los cuestionarios y entrevistas realizadas tras la lectura de A Duck Has an Adventure se observó la dificultad que tenía el alumnado para entender cómo la macroestructura en forma de árbol laberíntico del texto (Ramada Prieto, 2017) es fundamental a la hora de dar forma a su sentido global. Priorizaron, en su lugar, la importancia argumental de cada uno de los itinerarios y llegaron incluso a forzar la lógica del texto mediante la imposición de una reordenación cronológica que la obra voluntariamente niega. También se detectó una problemática de tipo más fenomenológico (Douglas, 
1994; Ramada Prieto, 2017) que reflejaba una forma frenética y superficial de confrontación actitudinal hacia el texto totalmente disonante con el lector implícito que este dibuja, lo que, de nuevo, dificultaba el proceso de construcción de sentido transversal en una obra de elevada carga existencial.

- Por último, la dinámica realizada con The Empty Kingdom dibujó dos problemas centrales. Primero, que a pesar de conformar un elemento definitorio de estas obras, hay un perfil de alumnado que tiene dificultades para entender el tipo de comunicación interactiva que proponen los juegos, de tal manera que el acto de comprender que en estas obras hay objetos que se han de coger para luego ser usados y resolver así una serie de secuencias lógicas que permiten el desarrollo argumental de la obra suponía una primera barrera competencial para muchos de los niños y niñas. Segundo, que incluso en el caso de que esta microestructura lúdica estuviese interiorizada por parte de ciertos alumnos, no era percibida y movilizada como lenguaje que ha de ser interpretado dentro del contexto general de la obra, sino que simplemente era convertida en una secuencia de objetivos inmediatos que debían ser resueltos sin mayor trascendencia temática. Esto, evidentemente, impidió a la mayoría de niños y niñas acceder a un tipo de lectura - llamémosla global - del texto justa con las pretensiones casi poéticas a las que apunta la obra. A partir de estos resultados, el proyecto debía diseñar e implementar una serie de dispositivos didácticos centrados en las dificultades detectadas para posteriormente evaluar su incidencia en el desarrollo competencial del alumnado con la LIJ digital. Así, y siguiendo esta misma estructura basada en las propiedades definitorias de la LIJD, se llevaron a cabo tres sesiones formativas para cada una de ellas.

El objetivo principal de la primera sesión era comenzar a desarrollar una conciencia interpretativa multimodal progresivamente más explícita y metarreflexiva y focalizada por igual en todas las sustancias expresivas involucradas en el mensaje-lenguaje escrito, música e imagen estática y en movimiento- Para ello, se decidió empezar con Lil' Red (Main, 2012), una versión de la Caperucita Roja para primeros lectores cuya característica principal es la de no utilizar ningún tipo de lenguaje verbal, salvo en el título. Al ser una obra fácilmente comprensible para un público con competencias lectoliterarias muy superiores a las exigidas por el lector implícito del texto, se pretendía que el alumnado fuese capaz de incrustarse mentalmente con comodidad dentro de la comunicación multimedia propuesta y pudiese reflexionar y manipular cognitivamente todos sus lenguajes. Lil' Red, además, destaca por la manera en que sustituye la caracterización física y moral de los personajes a partir del lenguaje verbal por un uso 
combinado de ilustración y sonidos que matizan todos los elementos. Por ejemplo, los personajes pequeños como la propia Caperucita o el pájaro cantor que la acompaña a lo largo de su aventura se comunican mediante instrumentos agudos y melodías amables, mientras que otros como el lobo feroz, un personaje más voluminoso y de dudosas intenciones, utilizan instrumentos graves y melodías que recuerdan por asociación simbólica y cultural (González Martínez, 1999) a situaciones peligrosas o intrigantes. El hecho de que el hipotexto (el cuento tradicional Caperucita Roja) fuese conocido por todos y de que el lector implícito de la obra fuese más joven que los sujetos elegidos para la investigación facilitaba la identificación de las funciones narrativas que cumplían los lenguajes no verbales, así como la posterior reconstrucción de su sentido. Esto permitía a los lectores reflexionar con mayor facilidad sobre la construcción de la obra.

La segunda obra elegida para esta sesión fue El visitante incómodo (Moving Tales, 2012), una adaptación audiovisual no interactiva de un cuento folclórico judío. La historia, centrada temáticamente en la importancia del empoderamiento vital a partir del trabajo diario y el esfuerzo constante, delega en la composición visual, el juego cromático y la gramática cinematográfica (Chatman, 1990) gran parte de su fuerza para construir las metáforas con las que se construye su texto. Los contrapicados muestran la debilidad física de su protagonista y el agigantamiento de una pobreza convertida en figura humanoide, el simbolismo de los campos que rodean la casa, verdecidos cuando la vida por fin prospera, el uso de los interiores y los exteriores y las luces que traspasan de un lado a otro para dibujar el aislamiento de los personajes. El nivel de simbolismo abstracto de la obra suponía un paso adelante en cuanto a las exigencias necesarias para desactivar su sentido, por eso se movilizó después de Lil Red y en forma de discusión colectiva guiada con la que intentar apuntalar esa reflexión multimodal activada con la Caperucita Roja.

Para finalizar la sesión, se decidió retomar el segundo capítulo de Inanimate Alice como forma de poner en funcionamiento todo el trabajo de interpretación audiovisual en una obra ya conocida, puesto que facilitaba distanciarse de la mirada puramente argumental y establecer un acercamiento más metarreflexivo sobre los modos en que la obra construye su discurso.

La segunda sesión, creada de nuevo a partir de las dificultades detectadas en torno a la disrupción discursiva durante la primera fase de la investigación, tenía dos objetivos que buscaban favorecer un desarrollo interpretativo más complejo y facilitar el construir sentido desde una mirada macroestructural, aunque apelaban a aspectos ligeramente diferenciados de la comunicación literario-digital. 
En primer lugar, se creía necesario trabajar con el alumnado un tipo de predisposición receptiva sincronizada con las exigencias de corte contemplativo que muchos de los constructos mundoficcionales de la LIJ digital proponen. Sean cuales sean los motivos detrás de la fosilización actitudinal detectada, lo cierto es que hubo problemas durante la primera fase para que los niños y niñas adoptaran una mirada pausada, atenta al detalle y a las relaciones transversales entre los eventos y existentes (Chatman, 1990) representados en A Duck Has an Adventure. Para ello, se decidió realizar un ejercicio de lectura/juego individual con una obra regida expresivamente por un principio de cosmicidad navegable como Samorost 3 (Amanita Design, 2016). Hablamos de "cosmicidad” o "Worldness” (Ramada Prieto, 2017; Klastrup y Pajares Tosca, 2004) cuando un texto basa gran parte de su intencionalidad estética en construir un mundo ficcional vivible y experimentable subyugando incluso para ello cualquier pretensión de unidad y acotación narrativa. La obra de Amanita Design es paradigmática en cuanto a esta propuesta de exploración contemplativa, al dejarnos guiar a un pequeño gnomo en sus deseos de convertirse en astronauta para descubrir y explorar una serie de planetas, cada uno de ellos con sus particularidades ecosistémicas, sus habitantes y sus rutinas vitales. La obra, a pesar de estar enmarcada dentro de un pretexto argumental que recuerda a la literatura de viajes, en realidad privilegia el ejercicio de descubrimiento pausado de los detalles que conforman esos mundos que visitamos. Ser buen jugador de Samorost 3, y por ende ser buen intérprete, se basa por encima de todo en entender cómo funciona cada uno de esos planetas, en querer saber cómo son sus habitantes y cómo se relacionan con su entorno.

Este era un marco textual ideal para promover de manera calmada y ligeramente pautada un tipo de acercamiento receptivo más cercano a la contemplación y a la exploración macroestructural que dirigida hacia la puramente narrativa o argumental. Pasear los extensos escenarios preciosistas con libertad o descubrir los carismáticos personajes escondidos con una mirada ralentizada y detallista son habilidades clave para el disfrute de obras con macroestructuras no lineales y que tienen en Samorost 3 un espacio de probatura, aprendizaje y disfrute ideal.

Tras este ejercicio paseístico, se diseñó una segunda actividad para que el alumnado volviese a A Duck Has an Adventure intentando que, esta vez, en grupos de tres o cuatro personas, reconstruyesen los principales itinerarios de la obra para luego ponerlos en común y reflexionaran de manera colectiva en torno a las confluencias argumentales y la importancia de analizar la obra como un todo para alcanzar su sentido global. 
Para finalizar esta serie de dispositivos formativos con el alumnado, se realizó una tercera jornada focalizada en las principales problemáticas observadas a la hora de interpretar los tejidos interactivos de las obras de LIJ digital.

Como decíamos anteriormente, una de las barreras detectadas fue la dificultad de cierto sector del alumnado para darse cuenta de que, en algunas de las obras de este corpus, existe una demanda de los textos para que el receptor participe activamente en las obras. En el caso concreto de The Empty Kingdom, esta dinámica retroactiva entre lector y texto se materializa a través del desplazamiento del personaje y mediante la recogida y utilización de ciertos objetos internos al mundo ficcional, algo que, como decimos, no fue interiorizado con facilidad por los sujetos.

Para trabajar esta mirada atenta a las demandas configurativas y participativas de algunos juegos, requisito indispensable para poder acceder a sus propuestas estéticas, volvimos a diseñar un dispositivo de juego individual ligeramente guiado. En esta ocasión, la obra elegida fue Botanicula, también del laboratorio checo Amanita Design (2014), una suerte de aventura gráfica en la que se ha de ayudar a una curiosa colección de personajes (una avellana, una seta, una pequeña rama de árbol, una semilla y una pluma) a salvar su hábitat de la oscura amenaza que pretende acabar con él. Aunque la obra tiene mucho de puro deleite contemplativo, mantiene un balance compositivo en el que los puzles y su resolución ocupan un lugar primordial dentro del desarrollo argumental de la obra y, por tanto, de su experiencia estética global.

Si Samorost permitía la libre exploración de sus escenarios, en Botanicula nuestros desplazamientos casi siempre están relacionados con llevar algún objeto hacia otro lugar, o con la necesidad de conseguir algo en ese sitio mediante pequeños retos de asociación e interpretación del mundo que se nos representa. En multitud de ocasiones, los cibertextos con este tipo de demandas interpretativas tienden a colocar al receptor en una posición de frustración (Aarseth, 2006) que debe aprender a resolver mediante la calma y la insistencia (tanto intelectual como puramente mecánica), competencias que se desarrollan progresivamente mediante, entre otras cuestiones, el bagaje, la(s) experiencia(s) y el disfrute concreto con este tipo de propuestas. Botanicula, sin embargo, lejos de colocar a su receptor ideal en una situación de posible frustración participativa en caso de no acertar con la correcta ejecución de sus puzles, consigue generar incluso desde el error una experiencia divertida y satisfactoria ante los diferentes resultados que se producen mientras se intenta resolver sus retos. Donde otras obras castigan, Botanicula recompensa con pequeñas secuencias de humor. 
Con la elección de esta obra, por tanto, se pretendía no solo paliar esa sensación de "ahogamiento" que parecía sufrir un sector del alumnado ante las secuencias de puzles de The Empty Kingdom, sino también generar una dinámica de participación activa ante la interactividad de la LIJD que les hiciese ver con mayor facilidad eso aparentemente tan sencillo: que en estos textos hay objetos que deben ser usados para desarrollar la cadena argumental.

El siguiente objetivo de la sesión era ya no solo activar la predisposición a la participación lúdica en el alumnado sino lograr que esa participación fuese convertida en un proceso de construcción de sentido en torno a los textos. A pesar de que The Empty Kingdom apunta hacia una lectura irremediablemente poética en la que acabamos sintiendo que encarnamos a un personaje consciente de que no sirve de nada ser el rey de un lugar vacío, los niños y niñas en su mayoría no lograron acercarse a esta idea y se quedaron en la mera reconstrucción del argumento. Por ello, tras la dinámica con Botanicula, se decidió movilizar en las mismas condiciones una obra aparentemente sencilla en su planteamiento discursivo: Metamorphabet (Vector Park, 2015), un abecedario interactivo creado por Patrick Smith, que en realidad esconde un subtexto lírico tremendamente sugerente.

La obra se compone de 26 escenarios, uno por cada letra del abecedario anglosajón, en los que la interacción con las letras-objeto que aparecen en la pantalla va generando una cadena de transformaciones que acaban siendo matizadas por una palabra que las define. Así, cuando aparece la letra E en pantalla y la tocamos, esta escupe de su interior un pequeño huevo de Pascua mientras se nos muestra un letrero con la palabra "egg" y escuchamos una voz en off que nos la lee en alto. Inmediatamente podemos dar de comer el huevo a la letra, quien inteligentemente abre la boca al tocar su comida para que, una vez masticada, la voz en off nos lea otro nuevo cartel: "eat". Siguiendo esta dinámica, el escenario, como el resto que compone la totalidad de la obra, evoluciona de palabra en palabra (Egg - Eat-Elephant-Earth) creando una serie de transiciones que un jugador desatento podría interpretar como meras yuxtaposiciones conceptuales pero que, desde una mirada más reflexiva, reflejan una clara intencionalidad lírica y relacional entre ellas.

Quizás el tono juguetón y humorístico del escenario relatado dificulte, aunque no oculta, esta pretensión poética de su autor, pero no hay más que reconstruir la secuencia ocurrida en la letra $\mathrm{G}$ para entender cómo emerge este lirismo si somos capaces de interpretar de manera consciente su gramática participativa, es decir, nuestras acciones en el cibertexto y sus consecuencias. Aquí, esta letra G se convierte, al ser tocada, en una guitarra (Guitar) que debido a nuestros gestos acaba cayéndose sobre un jardín (Garden) del que brotan unas flores. A estas 
flores, podemos arrancarles delicadamente los pétalos para que, tras emitir pequeños harmónicos de guitarra, se transformen en fantasmas (Ghosts). Una vez hemos quitado todos los pétalos de todas las flores de nuestro jardín, la única manera de que vuelvan a crecer las plantas es volviendo a rasgar las cuerdas de la guitarra, cuya música vuelve a hacerlas brotar. Si atendemos a la mera cadena audiovisual de la escena, o si no asociamos explícitamente nuestras acciones dentro del texto con sus consecuencias, podemos caer en el simplismo de pensar que Metamorphabet propone una cadena de palabras sin relación ninguna. Sin embargo, una lectura activa de toda su textualidad, participación lúdica incluida, evidencia un subtexto muy diferente: que la guitarra y las flores no son conceptos yuxtapuestos, sino que es la música que nosotros tocamos con la guitarra la que hace crecer la vida del jardín. Lo acotado de cada uno de los escenarios de Metamorphabet, así como la profundidad y fuerza de muchas de estas transiciones que parten realmente de ideas inicialmente sencillas de manejar, convertía a esta obra en una materia prima ideal para provocar esta activación interpretativa que se perseguía en la sesión.

Este objetivo se intentó terminar de afianzar a partir de una reconstrucción argumental en pequeños grupos de The Empty Kingdom y de una posterior discusión colectiva en la que el mediador debía dirigir al alumnado hacia una lectura relacional de ese argumento con la cadena participativa que propone su autor y hacer ver así a los niños y niñas la importancia de la construcción de sentido en torno a las acciones que nos proponen los textos interactivos.

\section{Seleccionar obras para evaluar el desarrollo competencial}

Una vez terminadas las tres sesiones formativas, se pasó a la tercera fase de la investigación en la que se pretendía analizar la posible incidencia que esta mediación formativa tendría en el desarrollo competencial del alumnado. El diseño de esta fase fue paralelo a la de la primera, debiéndose elegir por tanto tres nuevas obras, cada una de las cuales representaría una de las tres líneas que caracterizan a la LIJ digital. Con ellas se realizaron la lectura individual, los cuestionarios y las entrevistas antes mencionadas. Junto a la criteriología descrita en el comienzo, que delimitaba el rango de posibilidades a la hora de seleccionar los textos, se tomó también la decisión de que el lector implícito de esta segunda hornada fuese ligeramente más competente que el de las primeras, ya que, como decimos, el objetivo era analizar la posible evolución sufrida por el alumnado.

Dentro de este marco procedimental, se tomó la decisión de escoger Boum! (Les inéditeurs, 2015) para la parte dedicada a la multimodalidad. Esta obra, publicada como aplicación 
para dispositivos móviles, narra, sin palabras y utilizando principalmente los lenguajes visuales y sonoros, la historia de un trabajador consumido por su rutina laboral que ve en el arte su única escapatoria a la alienación. Uno de sus principales rasgos es la manera en que incorpora diferentes referentes estéticos de la historia de las vanguardias pictóricas para ir dando forma a su discurso, de tal manera que, por ejemplo, los momentos iniciales en los que se nos explica la cárcel que es para su protagonista su rutina de trabajo la ilustración bebe de la estética constructivista y la cartelería soviética de principios de siglo $\mathrm{XX}$, mientras que para sugerir la liberación espiritual que significa para su vida la cultura y el arte la composición visual apela directamente al modernismo abstracto de pintores como Kandinski. Este simbolismo de índole intertextual, por tanto, evidencia un paso más en cuanto a la complejidad interpretativa que demanda al lector respecto a la caracterización audiovisual más inmediata que demandaba un texto como Inanimate Alice. Además, junto a este entramado referencial que caracteriza el apartado gráfico, la obra utiliza toda una capa de significado sonoro que, de manera abstracta y en muchas ocasiones partiendo del contrapunto semántico respecto a la imagen, le añade muchos más matices al discurso a la vez que complejiza su acercamiento interpretativo.

Para la segunda sesión, relativa a la no linealidad del discurso electrónico literario, el texto elegido fue David Wiesner's Spot (Houghton Mifflin Harcourt, 2015) una aplicación para tabletas digitales cuya principal característica es la de presentar un mundo ficcional cuya estructura y organización no tiene posibilidad de ser ordenado desde ningún criterio jerarquizado: ni temporal ni espacial. Spot nos invita a explorar cinco escenarios diferentes con la particularidad de que, dentro de cada uno de ellos, existe una serie de objetos que actúan como portales, lo que nos permite viajar al resto de lugares que conforman la totalidad del mundo ficcional. Para que se entienda mejor, la obra es algo así como una serie de muñecas rusas en la que la muñeca grande contiene a una muñeca mediana que, en su interior, contiene tanto a la muñeca pequeña como a la grande de la que provenía. Esta ruptura de la lógica factual de nuestro mundo tiene como consecuencia fundamental esa heterarquía estructural de la que recién hablábamos y que impide, por tanto, recuperar un discurso lineal. Además, debido precisamente a esta estructura, la obra carece de una liminalidad textual que nos permita saber con claridad cuándo se ha "terminado de leer" su contenido. Esto coloca al lector en una posición experiencial muy diferente al tipo de contactos ficcionales que suele tener ya que, incluso suponiendo que el alumnado tenga costumbre de jugar obras videolúdicas en las que sus decisiones determinan el devenir de la narración, esta arborescencia narrativa suele generar una posible multiplicidad de 
itinerarios argumentales que desembocan en un número determinado de finales, pero no en una ausencia total de estos.

Sin embargo, a pesar del tinte postmoderno y de extrema complejidad vanguardista que podría significar para el lector esta heterarquía estructural, la obra tiende puentes interpretativos que le permiten anclarse de manera quasi narrativa. Así, a medida que navegamos estos escenarios veremos de manera recurrente una familia de personajes alienígenas a los que podríamos considerar los protagonistas de esta no-narración y que parecen estar viviendo una aventura interespacial, y otros secundarios que, sin estar presentes en todos los mundos, también demuestran tener sus propias motivaciones ficcionales dentro del entramado. Todo esto permite que, aunque la obra, por motivos de ordenación estructural, niegue su carácter estrictamente narrativo, esconda en su interior trazas de narratividad que facilitan su aproximación interpretativa y el disfrute de la experiencia ficcional y estética que propone.

Para acabar esta fase final del proyecto, se debía elegir una obra cuyo tejido participativo fuese representativo de las posibilidades semánticas que tiene este aspecto de la comunicación literaria digital infantil. El texto elegido fue Bla Bla, un ensayo sobre la comunicación humana desarrollado por Vincent Morriset (2012) para la National Filmboard de Canadá. La obra se divide en seis capítulos autoconclusivos, cada uno de los cuales aborda una cuestión específica del lenguaje, pero sin hacer uso de la palabra escrita más allá de los títulos de capítulo que los enmarcan. De esta manera, Bla Bla aborda, a modo de viaje secuenciado, la articulación sintáctica y semántica del lenguaje, su adquisición y aprendizaje por parte del hablante, sus primeros pasos como tal, el diálogo con el otro, la comunicación social y, para acabar, la manera en que usamos la palabra para expresar las emociones. Al realizar todo esto desde la ausencia de lenguaje oral o escrito, la obra construye un entramado simbólico en el que el resto de sustancias semióticas se combinan entre ellas para reflejar, con un elevado grado de abstracción, pero de manera inteligible, cada una de las ideas que pretende contar. Dentro de este ecosistema multimedia, el dialogo retroactivo entre las acciones del lector y las reacciones del cibertexto es una de sus materias discursivas fundamentales.

A modo de ejemplo, en el primero de sus escenarios, "Las palabras", la obra nos invita a pulsar una serie de bolas negras que aparecen en la pantalla y que, al hacerlo, se dividen en dos más pequeñas, cada una de las cuales emite un destello de color y una nota musical concreta. Este color y esta nota parecen simbolizar el significado de esas palabras que nacen de nuestra acción de ruptura previa. Además, según creamos más palabras a partir de nuestras pulsaciones, la pantalla va llenándose hasta que el propio algoritmo del cibertexto hace que, cuando dos de 
ellas se juntan demasiado, se fusionen entre sí. Este entramado de acciones y reacciones entre la participación del lector y el texto parece intentar reflejar, siempre desde la complejidad de la abstracción, el comportamiento sintáctico y semántico del lenguaje y la manera en que este se autorregula, que también se ve inevitablemente influenciado por sus hablantes.

A pesar de que The Empty Kingdom tenía una clara capa de significación poética a la que no era del todo sencillo acceder, parece evidente que el tipo de intérprete exigido por Bla Bla supone un paso más en la escalera competencial (Colomer, 2005), ya que se baña de abstracción desde su fachada, obligando al receptor a construir sentido con un nivel de simbolismo bastante complejo.

\section{Conclusiones}

En líneas generales, y teniendo en cuenta que algunos de los datos y resultados finales aún están en proceso de análisis, el desarrollo general del proyecto apunta claramente hacia la importancia y la urgencia de abordar la formación interpretativa del alumnado contemporáneo con una de las formas de culturas más representativas de la actualidad: la ficción digital. Los problemas detectados a la hora de que niños y niñas construyesen sentido con este tipo de obras - además de afianzar esta hipótesis ya explícita en el primer proyecto de investigación con literatura electrónica infantil (2011) del grupo de investigación GRETEL—, dejan entrever que el enfoque a la hora de diseñar los dispositivos tanto de investigación como didácticos, se ve beneficiado por el desglose teórico de la comunicación literario-digital infantil. Este enfoque facilita el aislamiento conceptual de las características específicas del corpus y, por tanto, el trabajo de detección de sus dificultades asociadas y de creación de acciones formativas con las que resolverlas.

Partir, por tanto, de la multimodalidad, la disrupción discursiva y la participación activa del lectousuario como elementos definitorios de la estética de la LIJ digital (y consecuentemente como eje de estructuración del diseño de la investigación y la selección de sus textos), creó una compartimentación enormemente funcional con la que perseguir los objetivos iniciales del proyecto e ir abordando de manera ordenada y efectiva los resultados que iban emergiendo durante su desarrollo. Poder identificar y aislar estrategias y problemas competenciales tan relevantes como los que hemos ido reflejando en este trabajo (dificultad para construir sentido de las sustancias semióticas no lingüísticas, incapacidad para interpretar activamente tanto el plano macroestructural de las obras como sus tejidos interactivos inmediatos...) ha sido fundamental para la evolución estructurada de la investigación, y marca una línea de trabajo sólida para el 
futuro tanto dentro del plano puramente académico como en posibles traslaciones didácticas que puedan derivarse del proyecto.

Sin embargo, este proceso de selección de obras representativas de la LIJ digital derivado de la criteriología descrita, también dibuja una serie de cuestiones conflictivas que se han de poner de relieve para posibles futuras acciones.

En primer lugar, y a pesar de que existen investigaciones recientes que respaldan su consideración como esfera cultural autónoma, el propio concepto de LIJ digital supone una delimitación conflictiva dentro del macrosistema que lo engloba, el de la ficción digital infantil y juvenil. La necesidad de buscar en los textos una predominancia compositiva hacia los elementos que tradicionalmente han definido lo literario, como la presencia explícita del lenguaje verbal oral o escrito, o la circulación social a través de canales herederos del circuito impreso, tiene como consecuencia la reducción drástica del número de obras que podrían considerarse "de nicho" y que obliga a mirar casi furtivamente hacia otras realidades estéticas como la del videojuego o la del hipercómic para así poder conformar un corpus que, al fin y al cabo, comparte con estas realidades más cuestiones que las que los diferencian.

En segundo lugar, y derivado de este escollo de delimitación textual, es innegable que existe una preocupante dificultad para seleccionar obras de LIJ digital a partir de unos criterios que tengan en consideración cuestiones básicas como la adecuación a rangos competenciales lectoliterarios concretos, la utilización de lenguas que no sean el inglés y que además cumplan unos mínimos de calidad. Esto tiene algunas consecuencias determinantes para el trabajo realizado a partir de este corpus que también queremos poner de relieve. Por un lado, la ausencia de textos en las lenguas co-oficiales del estado español obliga a movilizar obras que, o bien son mudas o bien hacen un uso marginal del lenguaje que permite construir significado a pesar de esta desviación idiomática. Esto, inevitablemente, condiciona el diseño de los dispositivos investigadores y de aula, ya que desequilibra la experiencia artística hacia una configuración multimodal en la que el lenguaje verbal está ausente, cuando precisamente lo que se pretende es abordar un acercamiento hacia los ecosistemas multimedia de la manera más global posible. Además, en casos como el de A Duck Has an Adventure, que, aunque tiene una utilización escueta, se comunica principalmente con su receptor en inglés escrito, resulta inevitable pensar que haya podido condicionar el tipo de acercamiento realizado por el alumnado y por tanto su interpretación de la obra.

Por último, esta escasez de obras tiene una consecuencia problemática a la hora de diseñar itinerarios de lectura con los que realizar cualquier tipo de formación interpretativa de 
investigación que involucre cualquier dispositivo didáctico y que sean longitudinales en el tiempo. Esto fue perceptible durante la investigación debido a la diferencia de complejidad que existía entre alguna de las obras elegidas para la primera fase y las de la tercera, y que pudo suponer un salto competencial excesivo para algunos perfiles dentro del alumnado. Además, debido a esta limitación en el corpus y en la propia temporalidad del proyecto, tampoco pudo diseñarse con absoluta comodidad un itinerario formativo intermedio que paliase ese posible salto en las exigencias interpretativas de las obras de la tercera fase. Esto es algo que debería tenerse en cuenta tanto en los resultados como en el futuro diseño de investigaciones, así como en la planificación didáctica de una educación ficcional atenta a esta realidad cultural.

Esperamos, por tanto, que en los próximos años logremos ser lo suficientemente flexibles en nuestra mirada y constantes en nuestra implicación formativa e investigadora como para vernos reforzados por este panorama de obras, por sus posibilidades y que podamos ir construyendo camino en la manera de emplearlas dentro del campo teórico y práctico de la educación literaria y ficcional.

\section{Referencias}

Aarseth, E. (1997). Cybertext. Perspectives on ergodic literature. Baltimore: The Johns Hopkins University Press.

Aarseth, E. (2006). Sin Sensación de final: Estética hipertextual. En M.T. Vilariño Picos y A. Albuín González (eds), Teoría del hipertexto. La literatura en la era electrónica (pp. 94-119). Madrid: Arco Libros.

Amanita Design (2016). Samorost 3., Versión 1.6. App para iOS.

Amanita Design (2014). Botanicula. Versión 1.1.3. App para iOS.

Chatman, S. (1990). Historia y discurso: la estructura narrativa en la novela y en el cine. Barcelona: Taurus.

Colomer, T. (2005). Andar entre libros. La lectura literaria en la escuela. México: Fondo de Cultura Económica.

Douglas, J. Y. (1994). How do I stop this thing?: Closure and Inteterminacy in Interactive Narratives. En G. P. Landow (ed.), Hyper/text/theory (pp. 159-188). Baltimore: John Hopkins University Press.

Ensslin, A. (2007). Canonizing hypertext: Explorations and constructions. Londres: Continuum. 
González Martínez, J. M. (1999). El Sentido en la obra musical y literaria: aproximación semiótica. Murcia: Universidad de Murcia.

Hayles, N. K. (2008). Electronic literature: New horizons for the literary. Notre Dame: University of Notre Dame Press.

Houghton Mifflin Harcourt (2015). David Wiesner's spot. Versión 1.2. App para iOS.

Klastrup, L. y Pajares Tosca, S. (2004). Transmedial Worlds. Rethinking Cyberworld Design CW 04' Proceedings of the 2004 International Conference on Cyberworlds (pp. 409416). Computer Society.

Kress, G. y Leeuwen, T. van (2001). Multimodal discourse: The modes and media of contemporary communication. London: Edward Arnold.

Landow, G. P. (2006). Hypertext 3.0: Critical theory and new media in an era of globalization. Baltimore: The John Hopkins University Press.

Les inéditeurs (2015). Boum! Versión 1.0. App para iOS.

Main, B. (2012). Lil’ red. Versión 1.03. App para iOS.

Manresa, M. y Real, N. (eds.) (2015). Digital literature for children. Texts, readers and rducational practices. Bruselas: Peter Lang.

Merlin Goodbrey, D. (2012). A duck has an adventure. E-merl.com. http://e-merl.com/stuff/duckadv.html

Merlin Goodbrey, D. (2015). The empty kingdom. E-merl.com. https://www.kongregate.com/games/Stillmerlin/the-empty-kingdom

Morisset, V. (2012). Bla bla. National Film Board of Canada. http://blabla.nfb.ca/

Moving T. (2012). El visitante incómodo. Versión 1.5. App para iOS.

Planells, A. J. (2015). Videojuegos y mundos de ficción. De Super Mario a Portal. Madrid: Cátedra.

Pullinger, K. y Joseph, C. (2005-2019). Inanimate Alice. The BradField Company y Dreaming Methods. http://inanimatealice.com/

Ramada Prieto, L. (2017). Esto no va de libros. Literatura infantil y juvenil digital y educación literaria (Tesis doctoral). Departament de Didàctica de la Llengua, de la Literatura i de les Ciències Socials, Universitat Autònoma de Barcelona, Bellaterra. Recuperado de http://hdl.handle.net/10803/460770

Ramada Prieto, L. (2018a). “Cariño, tenemos que hablar”. Ficción digital infantil y juvenil y su mediación. Revista Peonza, 126, 7-15. 
Ramada Prieto, L. (2018b). Infantil, digital, aumentada y virtual: los mil y un apellidos de una realidad literaria. Diablotexto Digital, 3, 8-31. Recuperado de https://ojs.uv.es/index.php/diablotexto/article/view/13565/12767

Torres, R., Machado, A. M., Alburquerque e aguilar, A., Andrade, J., Estefani, T., y Pereira, L. L. (2019). Literatura eletrónica para crianças: o caso do projeto "Murais e literatura: A criação digital em contexto educativo". Leitura: Teoria \& Prática, Campinas 37(75), 3966.

Ryan, M. L. (2006). Avatars of a story. Minneapolis: University of Minnesota Press.

Turrión, C. (2014). Narrativa infantil y juvenil digital. ¿Qué ofrecen las nuevas formas al lector literario? (Tesis doctoral). Departament de Didàctica de la Llengua, de la Literatura i de les Ciències Socials, Universitat Autònoma de Barcelona, Bellaterra. Recuperado de https://ddd.uab.cat/record/129320

Turrión, C. (2015). Electronic literature for children. Characterising narrative apps (2010-2014). En M. Manresa y N. Real (eds.), Digital literature for children: Texts, readers and educational practices (pp. 87-102). Bruselas: Peter Lang.

Unsworth, L. (2006). E-literature for children: Enhancing digital literacy learning. Londres: Routledge.

\section{Notas}

${ }^{1}$ Este artículo se inscribe dentro del proyecto "Enseñar a leer literatura digital” del grupo GRETEL (UAB) dentro del Programa Estatal de Investigación, Desarrollo e Innovación orientada a los Retos de la sociedad EDU201677693-R (2016-2019)

\section{Información sobre los autores:}

Lucas Ramada Prieto es doctor internacional en Didáctica de la Lengua y la Literatura con la tesis Esto No va de Libros: Literatura infantil y juvenil digital y Educación Literaria (2017). Es miembro investigador del grupo GRETEL de la Universitat Autònoma de Barcelona y centra su trabajo en el análisis teórico de formas digitales de ficción infantil y juvenil, y su relación con la educación literaria y artística.

E-mail: ramadaprieto@gmail.com

Celia Turrión Penelas es editora de literatura infantil y juvenil y doctora en Didáctica de la Lengua y la Literatura con la tesis Narrativa infantil y juvenil digital. ¿Qué ofrecen las nuevas formas al lector literario? (2014). Ha sido docente del Máster en Libros y Literatura para Niños y Jóvenes (UAB), y ha investigado de manera independiente junto al grupo de estudio de literatura infantil y juvenil, arte, libros y lectura Círculo Hexágono.

E-mail: cel_tp@hotmail.com 
Para citar este artículo:

Ramada Prieto, L. y Turrión Penelas, C. (2019). La selección de obras para la investigación en LIJ digital: de la teoría a la recepción. Bellaterra Journal of Teaching \& Learning Language \& Literature, 12(3), 44-64. DOI: https://doi.org/10.5565/rev/jtl3.839 